AROUEOLogía Y SOCIEDAD

№ 28, 2014: 61-70

1SSN: 0254-8062

RECIBIDO: MARZO DE 2014

ACEPTADO: OCTUBRE DE 2014

\title{
LA ESCUELA NORMAL DE VARONES DE LIMA, ANTECESORA DE LA UNIVERSIDAD NACIONAL DE EDUCACIÓN LA CANTUTA, CUMPLE 108 AÑOS DE SU REFUNDACIÓN
}

\author{
DAVID AgUILAR BERROSPI \\ Universidad Nacional de Educación EnRIQUe Guamán y VALLE - La CANTUTA \\ david_aguilarb@yahoo.com
}

\section{RESUMEN}

A fines del siglo XIX y en las primeras décadas del siglo XX, se constituyó la época de oro de la vieja oligarquía peruana. Bajo el impulso de una extraordinaria dinamización mercantil, una fracción propietaria ligada a la exportación, las finanzas, el comercio y la especulación logró organizarse políticamente a nivel nacional. Aunó su peso político a través del control directo del aparato estatal: Gobierno, Parlamento, Poder Judicial, Universidad, etc. Jorge Basadre la denominó la Republica Aristocrática. Durante este período, José Pardo actualizó la reforma educativa aprobada durante el gobierno de su padre Manuel Pardo en 1876, al promulgar las leyes № 74 y la № 162 del 27 de noviembre y del 05 de diciembre de 1905 respectivamente. El 14 de mayo de 1905 inauguró la Escuela Normal de Varones, antecesora de la UNE, La Cantuta, en el local provisional que se le concedió en la calle del Corcobado, ubicado en el Cercado de Lima. Concurrieron al acto solemne el entonces Presidente de la República, doctor José Pardo y Barreda, el ministro de Instrucción Pública doctor Jorge Polar y su Director Encargado, doctor Isidoro Poiry. Enrique Guzmán y Valle, en abril de 1909 es nombrado docente de la Escuela Normal. En 1915 fue nombrado Director de la Escuela hasta su muerte en 1923.

Palabras Clave: República Aristocrática, Segundo Civilismo, modernización capitalista, pensamiento positivista, censo, reforma educativa, sectores populares, Escuela Normal, profesión magisterial, patrimonio monumental.

\footnotetext{
Abstract

In the late nineteenth and early twentieth century, it was the golden age of the old Peruvian oligarchy. Under the impetus of an extraordinary commercial revitalization, owns a fraction linked to the export, finance, trade and speculation organize politically managed nationally. Increase political importance take over of state apparatus: Government, Parliament, Judiciary, University, etc. Jorge Basadre called aristocratic republic. During this time, José Pardo called educational reform passed during management of his father Manuel Pardo in 1876, to enact laws N '74 and No. 162 of November 27 th and December 5th 1905 respectively. On 14 May 1905 opened Normal School for Boys, predecessor of UNE, La Cantuta, in temporary premises was granted in Corcobado Street, located in Lima Down Town. Ceremony was attended by President of the Republic, Dr. José Pardo y Barreda, Minister of Education Dr. Jorge Polar and Acting Princi-
} 
pal , Dr. Isidoro Poiry. Enrique Guzmán y Valle, in April 1909 he was appointed professor at Ecole Normale. In 1915 he was appointed Principal at School until his death in 1923.

KeYWoRDS: Aristocratic Republic, Second civility, capitalist, positivism, census, education reform, grassroots, Normal School, teaching career, monumental heritage.

\section{Contexto ECONÓMico}

Hacia mediados de la década de 1890, se dio inicio, en algunas regiones del Perú, a un proceso intenso, nuevo y fundamental. Lentamente, no sólo se van a ir recuperando los niveles de producción logrados antes de la guerra del Pacífico, sino que un desarrollo mercantil de nuevo signo -el del capitalismodefinirá el contexto socioeconómico de la época. Como ocurrió antes de aquella guerra, el auge mayor provino también ahora de los sectores productivos orientados al mercado mundial, distinguiéndose, eso sí, dos etapas bastante marcadas: a) la correspondiente a las dos primeras décadas del siglo XX, con predominio de la producción agropecuaria: azúcar, algodón, caucho, lanas, productos que totalizaron más del 50\% del valor de las exportaciones peruanas, mientras que en este mismo periodo, la minería tuvo un menor impacto: cobre y petróleo, los dos principales productos para el mercado mundial, fluctuaron entre el 10 y $20 \%$ del total de exportaciones del país, tendencia que se mantuvo fundamentalmente hasta antes de la Primera Guerra Mundial; y b) la década de 1920, donde la minería tuvo un mayor desarrollo y alcanzó una posición de preeminencia en el cuadro de las exportaciones nacionales.

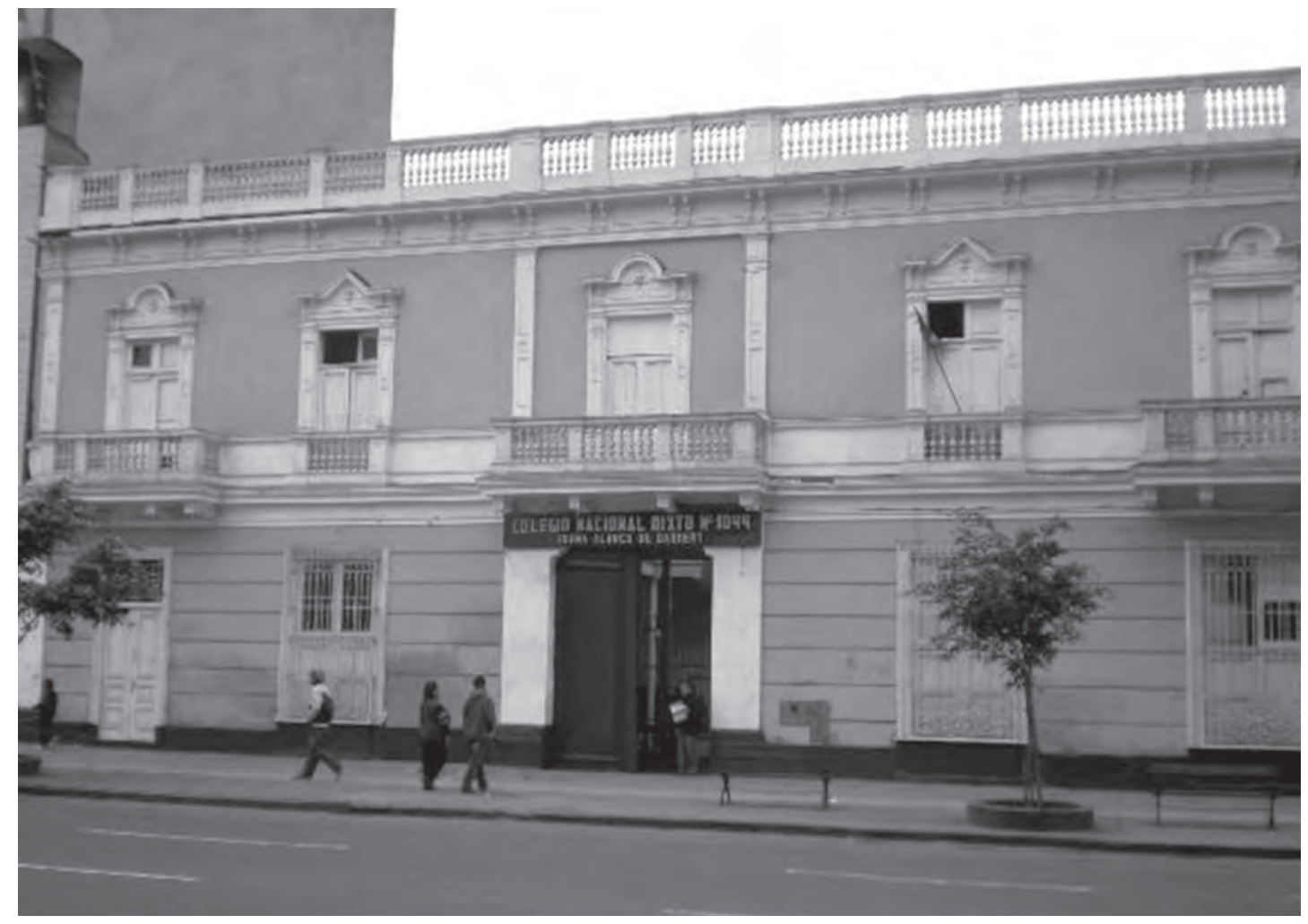

Figura 1. Vista del local de la Escuela Normal de Varones de Lima. 
En esta expansión participaron activamente tanto capitales extranjeros como locales. En algunos casos, con recursos acumulados previamente durante el boom guanero del siglo XIX (tal la situación de un capital como el de Grace); en otros, significó realmente una inyección externa de recursos provenientes del exterior que se insertaron en un sector del país (aquí cabe el ejemplo de la empresa Cerro de Pasco). Otro tanto ocurrió con los capitales nacionales que se iniciaron. Algunos, son de no muy lejano origen mercantil guanero. Otros, como en la región central andina, empezaron como comerciantes- mineros, abordaron luego la explotación agropecuaria e intentaron más adelante procesos de transformación productiva notables, sobre todo, si hacemos un balance del desarrollo de la agricultura y ganadería modernas en el conjunto de la región andina peruana. A su turno, la expansión minero-agropecuaria impulsó el desarrollo de un nuevo circuito bancario, de compañías de seguros, de una incipiente industria manufacturera, así como de empresas de servicio público (de tranvías, electricidad, etc.). Este vertiginoso crecimiento, luego de la severa postración que trajo consigo la guerra del Pacífico, suscitó un gran entusiasmo en los estratos altos de las clases dominantes y en los núcleos intelectuales, ambos ligados umbilicalmente hasta aquel momento.

Se esperó un rápido y floreciente desarrollo capitalista, una expansión productiva extraordinaria que a su vez impulsaría un desarrollo social que de algún modo acabaría o minimizaría siglos de viejas ataduras, que restaría antiguas cicatrices, que sería en fin, el inicio de la esperada "grandeza". A partir del análisis de la conformación y participación de la clase dominante en el Perú en las primeras dos décadas del siglo XX se sintetiza en la coyuntura del segundo civilismoque va desde 1890, aproximadamente, hasta fines de la segunda década de este siglo. Constituyó el período de oro de la clase dominante peruana. Durante estos años, un horizonte de proyectos y posibilidades cruzó el firmamento civilista. Bajo el impulso de una extraordinaria dinamización mercantil, una fracción propietaria ligada a la agricultura de exportación, las finanzas, el comercio, la especulación, logró organizarse políticamente, dando en cierto modo una dimensión nacional a su hegemonía política. Es lo que podríamos llamar la República Civilista.

\section{CONTEXTO SOCIAL}

A principios del siglo XX, Lima estaba rodeada de haciendas y chacras que la urbanización de los años veinte absorbería paulatinamente. La mayoría de sus habitantes vivían en condiciones de hacinamiento. Recién en 1870 llegó el agua potable, sólo para algunos sectores. Esta situación se agravó con el crecimiento de la población de sectores populares en una ciudad que no estaba preparada para albergarlos. "Según el censo de 1908, en los distritos más pobres (Barrios Altos, La Victoria, Rímac) predominaban las casas de adobe ( o quincha), con carencias de agua y desagüe, y donde habian zonas tugurizadas con un promedio de hasta 50 personas por cada casa de vecindad. Entre los años que van de 1900 a 1931, la población de Lima pasó de 150,000 habitantes en 1900 a 224,000 en 1920 y 376,000 en 1931. Esto representa un crecimiento de 150\%. Pero además, la tasa de crecimiento de la población de los sectores populares fue del orden del 200\%, o sea mayor que la de la ciudad en su conjunto. Las situaciones descritas explican la existencia de enfermedades que elevaban las tasas de mortalidad, como la tuberculosis, fiebre tifoidea y gripe" (Gonzales 2005: 143).

La relativa modernización de Lima se focalizó en ciertos aspectos y zonas que no eliminaron su panorama preindustrial característico. Como consecuencia de los cambios descritos, a inicios del siglo XX se formaron nuevos espacios de socialización y de interacción que pronto iban a posibilitar acciones colectivas. Por otro lado, el reducido espacio que constituía el llamado "tablero de Pizarro" forzó una obligada interacción, pues al lado de las mansiones señoriales vivían obreros y artesanos en casonas que fueron subdivididas y arrendadas, así como miembros de la "clase media" que se hallaban muy preocupados por su status. Al lado de estos hechos concretos existió una demarcación simbólica demarcada por el río Rímac. "El río separaba en dos a la ciudad: el centro aristocrático, donde se concentraban las instituciones del poder político y social (Palacio, parlamento, municipalidad, etcétera), y el barrio del Rímac, ubicado detrás de la casa de gobierno. Aquél era el lugar de las élites, éste era el espacio de los pobres. Abajo del 
Puente, lugar de negros y mestizos, fue un referente central en la consolidación de la cultura criollo-popular; ahí la política oficial apenas llegaba con la formación de algunos clubes políticos. En el otro lado del río se ubicaban importantes barrios populares como La Parada, Borbones, Cangallo, los Barrios Altos, La Victoria" (Gonzales 2005: 144).

\section{ConteXTo POLÍTico}

Para las elecciones de 1899, Piérola designó como su sucesor Eduardo López de Romaña. Éste fue elegido presidente para el período 1899-1903. "Cuando en 1899 Piérola abre Palacio de Gobierno a Lopez de Romaña, están dadas las condiciones para la consolidación del civilismo en el poder legitimado" (Yepes 1971:178). Para las elecciones de1903, las alianzas ya se habían modificado, pues triunfó el civil-constitucionalismo, llevando a la presidencia a Manuel Candamo (presidente del Partido Civil). Postularon como vicepresidentes Lino Alarco (que murió antes de juramentar al cargo) y a Serapio Calderón, del Partido Constitucional. Como presidente, Candamo no promovió una política conservadora. Por el contrario, renovó la política dando paso a una nueva generación. Dentro de ésta José Pardo, Manuel Barrios y Augusto B. Leguía desplazaron en los puestos de gobierno a los "viejos civilistas", como Isáac Alzamora, Alejandro Deustua y Domingo Almenara. En esta pugna Alzamora, al verse en minoría renunció a la presidencia del Partido Civil. José Pardo fue elegido en su remplazo.

En 1904 se hizo evidente una escisión generacional dentro del Partido Civil. Ese año se dio una lucha por el control del Comité Central entre los partidarios de la candidatura presidencial de Isáac Alzamora y los de la de José Pardo. Los “jóvenes turcos” de Pardo (Miro Quesada 1961: p.364) triunfaron y obligaron a Isáac Alzamora, Ántero Aspíllaga y Alejandro Deustua a salir del comité. Esta fue una lucha estrictamente entre la clase dominante que representaba un cambio de dirección política. Si el nuevo grupo tenía de alguna manera un pensamiento más progresista, aún representaba los mismos intereses. Aspíllaga era un hacendado azucarero, pero Pardo también lo era. El 13 de setiembre de 1904 la mayoría de la Comisión de Cómputo del Congreso, emitió un dictamen declarando a José Pardo como presidente de la república. Este dictamen fue aprobado por la mayoría del Congreso.

A finales del S. XIX en la Universidad de San marcos, las facultades de Derecho, Letras, Ciencias Políticas y Medicina, se convierten en santuarios de la nueva perspectiva. Eminentes y doctos profesores vierten las nociones de: "método científico", "orden y progreso", a través de los cursos que dictan en la vieja casa de estudios. Los más importantes fueron: Javier Prado Ugarteche, Mariano H. Cornejo, José Matías Manzanilla y Manuel Vicente Villarán. "Estos académicos formaban parte del Partido Civil, expresión política de la fracción hegemónica. Aunque al interior de éste representaron y dirigieron el ala progresista, en sus estudios - todos eran abogados-se fraguaban y legitimaban los mecanismos concretos, los contratos mercantil financieros más importantes, estos es, los que efectuaban los grupos europeos y norteamericanos, que controlaban la economía peruana. El desarrollo del país para estos académicos, significaba el desarroIlo del sistema capitalista de libre competencia, y en particular, caso de Prado y Villarán, el modelo a seguir era Estados Unidos". (Yepes1971:166).

Incapaces de examinar la dinámica interna, los procesos y estructuras que alguna manera la clase dominante legitimaba no hacían sino acentuar más la dependencia de nuestra economía. Sus planteamientos meramente formales, de carácter jurídico-literario, tenían escasas probabilidades de difundirse en un país con la mayor parte de su población analfabeta y de escasa participación cultural por lo que consideraron que la educación sería la vía por la que la sociedad se integraría espacialmente y adquiriría los perfiles de una sociedad moderna. Acordes pues con el pensamiento positivista, en la medida que éste señalaba el rol fundamental de la ciencia como factor básico para el "progreso" de las naciones, pensaron que la educación traería consigo necesariamente el desarrollo nacional, insistiendo por ello en la reforma de las instituciones pedagógicas en el contexto de una nueva orientación científica y tecnológica. Javier Prado y Manuel Vicente Villarán son una clara expresión de esta perspectiva, en donde la educación deviene en el medio fundamental para el progreso. Pero a diferencia 
de Prado cuyas exhortaciones carecían de concreción en torno a los mecanismos con que los cambios que postulaban deberían efectuarse, Manuel Vicente Villarán ya en 1905 planteó el desarrollo económico a la base de cualquier intento en la expansión de la educación nacional. Ahora bien, aunque estos atisbos no llegan a penetrar la matriz de la sociedad, esto es su estructura de clases, "guardan profunda diferencia con los planteamientos de Deustua, para quien la educación debía orientarse selectivamente hacia la clase dominante, desde que el progreso reposaba en la posibilidad de conformar una élite ilustrada capaz de llevar al país a cumplir sus metas de desarrollo". (Yepes 1971:167).

Este pensamiento, de perspectiva positivista, fue asumido por los académicos más representativos de esta época que fueron: Francisco García Calderón Rey, José de la Riva Agüero y Osma y Víctor Andrés Belaúnde, entre otros. Para García Calderón era necesaria la vigencia de una élite ilustrada, ésta la constituía el civilismo quien era el llamado a imponer el orden, "base del progreso". A diferencia de García Calderón, Riva Agüero y Belaúnde tendrían un período más breve de influencia positivista. El entusiasmo que esta perspectiva infundía en García Calderón se explica en la medida que desde adulto, la mayor parte de su vida transcurrió en Europa, no siendo casual por ello que escribiera sus dos obras más importantes (El Perú Contemporáneo y Las Democracias Latinas) directamente en francés. Por ello, con su énfasis en la expansión de la tecnología, la inmigración europea y la ampliación de los sectores medios progresistas, buscaba abrir las avenidas de la modernización y del progreso al país.

Estas ideas positivistas, en cambio, tuvieron su mayor impacto sólo durante los años universitarios de Riva Agüero y Belaúnde, período coincidente con aquellos años (1895-1910) en los cuales el país fue inundado con el espejismo de la "renovación", "modernización”, "innovación” y en los cuales el modelo político civilista encontró un soporte ideológico. "Sin embargo, al resquebrajarse la república civilista, por las contradicciones internas y desplazamientos de poder en el nivel metropolitano del sistema capitalista, el anterior entusiasmo fue decreciendo en ambos, al punto que no tardaron en abandonar esta dirección en favor de una posición idealista, retornando así a un catolicismo de trasfondo tradicional y jerárquico". (Yepes 1971:168). Si bien para Belaúnde, la acción política sólo descubriría el camino para su capacidad de transformación en el estudio científico de la sociedad peruana, estudio que haría viable el conocimiento de los obstáculos que detuvieron su desarrollo, esto no indicaría los medios para perfeccionar las instituciones políticas. Estos planteamientos fueron superficiales en la medida que ellas mismas no se iniciaron ni desprendieron de un análisis de los soportes estructurales sobre los que reposaba el modelo exportador entonces vigente, ni se plantearon las posibilidades que dichas estructuras permitían afín de ser viable su ansiada meta de elevar la cultura nacional ahora convertida en un imperativo histórico. Esta incapacidad para comprender el carácter del capitalismo dominante y la compleja dinámica de una sociedad dependiente, determinó que al hacer crisis la República Civilista en 1919, derrumbado el mito del progreso y de la transformación nacional, desapareciera en estos ideólogos el inicial entusiasmo por la modernización, la inmigración europea y la educación de cuño civilista.

Esta fue la distancia que medió entre los intelectuales y los políticos civilistas. Estos últimos, gracias a su práctica cotidiana eran conscientes de su debilidad económica frente al capitalismo internacional así como los límites hasta donde era posible negociar desde una posición de intermediación política. Aunque tanto Belaúnde como Riva Agüero lograron tener una notable influencia en la política educacional de José Pardo, en realidad la República Civilista les otorgó una escasa participación en las decisiones. En general, pues, tanto el Partido Civil como el Demócrata dieron un débil acceso al poder a los intelectuales jóvenes, circunstancia que favoreció el que éstos explicaran su frustración y desengaño por una falta de oportunidad política. Lo que agravó su crisis interna fue la nominación de Augusto B. Leguía para suceder a José Pardo (durante su primer gobierno 1904-1908), a instancias de este último, y desde que Leguía fue considerado por los civilistas como un advenedizo. 


\section{Contexto educativo}

Lima a inicios de 1900, fue una ciudad relativamente instruida, aun en los sectores populares, pero también existió una jerarquización de los grupos étnicos en lo referente a su grado de instrucción. Veamos el cuadro siguiente:

Cuadro Comparativo: Grado de Instrucción (Por mil)

\begin{tabular}{|l|c|c|c|c|c|c|c|c|}
\hline & \multicolumn{2}{|c|}{ Leen y escriben } & \multicolumn{2}{c|}{ Leen pero no escriben } & No leen ni escriben & \multicolumn{3}{c|}{ Total } \\
\cline { 2 - 9 } Grupo étnico & Absoluto & Relativo & Absoluto & Relativo & Absoluto & Relativo & Absoluto & Relativo \\
\hline Blanco & 47,171 & 942 & 1,022 & 21 & 1,874 & 37 & 50,067 & 1,000 \\
Meztizo & 32,407 & 803 & 2,011 & 50 & 5,472 & 137 & 39,890 & 1,000 \\
Indígena & 12,004 & 664 & 1,169 & 61 & 5,779 & 306 & 18,952 & 1,000 \\
Negro & 4,051 & 632 & 468 & 76 & 1,573 & 206 & 6,092 & 1,000 \\
Asiático & 1,020 & 203 & 72 & 14 & 3,935 & 783 & 5,027 & 1,000 \\
\hline Total & 96,653 & 805 & 4,742 & 40 & 18,633 & 155 & 120,028 & 1,000 \\
\hline
\end{tabular}

El cuadro revela que mientras el grupo étnico blanco ostenta los niveles más altos de alfabetismo (963 de 1000 saben leer y escribir, casi el 100\%), la escala va reproduciendo la ubicación de los grupos étnicos en la sociedad limeña, ubicándose el contingente asiático en el último lugar con los mayores niveles de analfabetismo (783 de 1000 no saben leer ni escribir, el 78.3\%). "De estos datos se constata fácilmente cómo las "razas de color" ( o "inferiores") tienen los niveles más bajos de alfabetización. Esto reafirma que la dominación social tenía también un carácter racial." (Gonzales 2005: 155).

\section{La obra educativa de José Pardo y BarReda}

Las bases que puso Piérola para un cambio educativo, al nombrar una Comisión que redactó el Proyecto de ley Orgánica de Instrucción en 1895, con autorización legislativa del 20 de noviembre de 1899, dieron como resultado la Ley orgánica de Instrucción, promulgada el 9 de marzo de 1901 por el presidente Eduardo López de Romaña. Posteriormente, Pardo y su ministro Jorge Polar, durante su gobierno, consideraron urgente una reforma total de la educación y un incremento preferente a la Primaria, porque las deficiencias de ésta traían consecuencias negativas para los otros grados. Resolver el problema de la educación elemental era, pues, contribuir a la solución de un tema nacional como era el mejoramiento de la vida de la población. "Paralelamente la influencia de su gestión se hacía patente en la educación laboral, normal, secundaria y superior. En un discurso de clausura universitaria, Pardo manifestó que la prosperidad la fuerza, el porvenir, en suma, de la República, requieren que el Estado desarrolle la educación nacional". (Valcárcel 1975: 193). Durante su primer gobierno, José Pardo, realizó una obra educacional de grandes alcances. Se tuvo en cuenta los aspectos siguientes: a) el fomento de la instrucción primaria; b) la mejora de locales y material escolar; c) el estímulo a la profesión magisterial; d) el fomento de la instrucción técnica y de la secundaria; e) la organización del Ministerio de Instrucción pública, y f) la cordialidad en las relaciones con las universidades. De los aspectos en referencia consideramos analizar lo relacionado al estímulo a la profesión magisterial.

El 09 de marzo de 1901 el gobierno de Eduardo López de Romaña promulgó la Ley Orgánica de Instrucción. En el Capítulo XV concerniente a las Escuelas y Cursos Normales, se precisa lo siguiente:

"Art. 134. Habrá por lo menos, tres escuelas normales para varones y otras tres para mujeres. Estas escuelas tendrán por objeto formar preceptores y preceptoras de segundo grado y se establecerán en Lima y en las capitales de Departamento que en el Norte y Sur de la República sean los más centrales, a juicio del gobierno. 
Art.135. Cada escuela normal tendrá anexa una escuela de aplicación, en la que los normalistas se ejercitarán en la práctica de la enseñanza.

Art.136. La duración y el orden de los estudios y el reglamento por el cual se rijan esas escuelas, se formarán por el Consejo Superior.

Art. 137. Los directores y profesores de las escuelas normales serán nombrados o contratados por el gobierno.

Art. 138. Para ser nombrados ó contratados, se requiere tener título de preceptor de segundo grado, adquirido en escuela normal, nacional ó título equivalente en escuela extranjera, tener cuando menos 25 años de edad los Directores y 21 los profesores y reunir las demás condiciones de moralidad y salud que se determinarán en esta ley para los preceptores.

Art. 139. Los gastos de las escuelas normales serán de cuenta del Gobierno.

Art. 140. Las plazas de alumnos de las escuelas normales se proveerán por el Supremo Gobierno, de entre los jóvenes que, solicitándolas, reunan las condiciones de edad y demás requisitos señalados en el Reglamento de dichas escuelas.

Art. 141. El Consejo Superior, en su oportunidad, determinará los Departamentos que constituyan la circunscripción dependiente de cada escuela normal, así como el número de alumnos que á cada uno de ellos corresponda en cada escuela y las demás disposiciones relativas á dichos alumnos.

Art. 142. Los alumnos internos á quienes el Gobierno pague su educación, están obligados á servir cinco años en la primera enseñanza, con la remuneración que los presupuestos determinen para los cargos que ocupen.

Art. 143. Las escuelas normales hallan bajo la inspección y vigilancia del Consejo Superior; el cual ejercerá esta atribución por medio de la Dirección de primera enseñanza, en la Escuela Normal de Lima, y de la Comisión de Delegados del respectivo Departamento, en las del Norte y Sur de la República".

\section{INAUguración de La Escuela Normal dE VARONES}

Hace 108 años empezó el funcionamiento regular de la Escuela Normal de Varones, antecesora directa de la Universidad Nacional de Educación Enrique Guzmán y Valle. Aconteció la refundación definitiva de la Escuela Normal de Varones el domingo 14 de mayo de 1905 en el local provisional que se le concedió en la calle del Corcobado. Concurrieron al acto solemne el Presidente de la República, doctor José Pardo y Barreda, el ministro de Instrucción Pública, doctor Jorge Polar, y el Director Encargado de la flamante institución formadora de maestros, doctor Isidoro Poiry entre otros altos funcionarios. La inauguración de la Escuela se consideró como un significativo avance para el desarrollo nacional y como una obra que redundaría en mayor simpatía para la gestión del presidente Pardo. Hasta entonces, y con los problemas que sufriera la Escuela Normal a lo largo del siglo XIX, los maestros de escuela se formaban casi de manera autodidacta, al no existir formalmente una institución que los formara profesionalmente. La flamante institución se entendía como el lugar donde el futuro maestro adquiriría conocimiento y aprendería a mantener un diálogo constante con sus compañeros, relación que le proporcionaría aptitudes válidas para su aplicación en la tarea educativa.

El director encargado de la Escuela Normal Isidoro Poiry, de nacionalidad belga, propuso para nuestro país una reforma con criterio científico. Según él se podría proponer la organización de la enseñanza normal de otros países, pero examinando enteramente esta organización, creada casi por todas partes desde hace medio siglo, pensaba que ésta no respondía a todas las exigencias modernas. La escuela, decía, es en gran parte el resultado del empirismo, no es una casa que ha sido creada sobre bases exactas; ella es consecuencia de transformaciones, buenas y malas, dictadas en los cursos de los años. Pues, los numerosos cambios que se desarrollaron tuvieron casi siempre, como punto de partida, consideraciones de orden filosófico, cuando el dominio científico es capaz de indicar las medidas propias a hacer lógico y eficaz el desenvolvimiento del niño. Además planteó que la escuela es la gran productora de las fuerzas físicas, intelectuales y morales de un pueblo. La formación de maestros se 
sobrepone a todo. La enseñanza popular en un país es de mucha más importancia que la enseñanza media y superior y la educación no será buena sino con hombres que hayan recibido una preparación especial, que consideren la pedagogía como ciencia, que conozcan exactamente la naturaleza física, intelectual y moral del niño. José Antonio Encinas, al respecto señaló que: "Se funda la Escuela Normal sin local apropiado, sin profesores idóneos, sin orientación definida en sus propósitos. Frente a ella colocan a un maestro belga, el doctor Isidoro Poiry, que labora un magnífico plan de estudios superior a los de Europa, quizá único. El propósito de Poiry es preparar al educador más que de simple y tradicional maestro de escuela. Para Poiry formar leaders es una cuestión esencial. Comprende que el Perú necesita de un verdadero Estado Mayor que dirija la más difícil de las campañas que el país tiene por delante. Piensa que el maestro puede mejorar la técnica escolar, perfeccionar el método, pero juzga que el país requiere algo más que un preceptor. Sabe que el Perú está anquilosado por una serie de prejuicios que no basta para destruir la simple y aislada acción docente. Pero eso, orienta la Escuela Normal en el sentido de un verdadero centro de cultura pedagógica superior. Exige a los candidatos a estudiantes normalistas poseer instrucción secundaria, y por este hecho. Equipara los estudios de la Escuela Normal a los de la Universidad. El futuro educador ya no debía salir de la Escuela primaria con escasos conocimientos de orden general, y sin ninguna preparación para asumir el difícil papel de maestro. Hasta entonces los preceptores eran diplomados teniendo como base un examen de materias de instrucción primaria y unas cuantas y elementales nociones de Pedagogía". (Encinas 1932:11-12).

\section{CONCLUSIÓN}

Por patrimonio monumental se entiende el conjunto de construcciones, generalmente arquitecturales, que a causa de su belleza, espectacularidad técnica, grandeza, "monumentalidad", singularidad, emotividad, historicidad o significatividad han sido consideradas y valoradas por una determinada sociedad. El patrimonio tiene un papel importante en la formación y configuración de una personalidad colectiva; representa en cierta manera una herencia del pasado, pasado a lo largo del cual se ha construido una determinada formación social y cultural. En este sentido el patrimonio- herencia forma parte insoslayable de la personalidad del presente. El patrimonio monumental, por su especial significatividad emblemática, acostumbra a ser un lugar de trabajo interdisciplinar y sobre todo contribuye a que el conocimiento de la historia debe servir para dar a conocer a las nuevas generaciones a apreciar y disfrutar de todos los vestigios del pasado, no únicamente de las obras o monumentos famosos, sino, aprender a mirar a su alrededor con "ojos históricos", incluso a valorar adecuadamente los restos "menos valiosos" desde un punto de vista material y verlos como objetos directamente ligados a nuestros antepasados, a las condiciones de su vida cotidiana, sus anhelos, frustraciones y luchas por mejorar sus condiciones de vida material y cultural. En consecuencia debemos solicitar a las autoridades competentes conformen una Comisión multidisciplinaria a efectos de rescatar, restaurar, conservar y valorar culturalmente el local que actualmente ocupa el Colegio Nacional Mixto № 1049 Juana Alarco de Dammert, sito en el Jr. Cusco № 426, Lima. Local en el que hace 108 años empezó el funcionamiento regular de la Escuela Normal de Varones, antecesora directa de la Universidad Nacional de Educación Enrique Guzmán y Valle. Cuya ceremonia inaugural aconteció el domingo 14 de mayo de 1905. Sin embargo, es necesario recordar que el 6 de julio de 1822 el Libertador José de San Martín fundó la primera Escuela Normal del Perú. Por lo tanto debemos prepararnos para la celebración del bicentenario de su fundación. 


\section{BiBLIOGRAFÍA}

\section{Fuentes primarias impresas:}

Leyes y Normas Jurídicas de la época de estudio

Ley Orgánica de Instrucción del 09 de marzo de 1901.

Ley № 74 de Supresión del Consejo Superior de Instrucción pública del 27 de setiembre de 1905.

Ley № 162 de Reforma de la Instrucción elemental del 05 de diciembre de 1905.

Ley № 553 Consignando una partida en el Presupuesto General para el pago de los profesores contratados en Alemania del 10 de octubre de 1907.

\section{Fuentes secundarias impresas}

AGUILAR, David

2010 Historia del Perú Contemporáneo. Lima: Ediciones UNE.

BASADRE, Jorge

1970 Historia del Perú. Lima: Ed. Universitaria.

BONILLA, Heraclio

1974 Guano y Burguesía. Lima: IEP.

BOURRICAUD, Francois

1989 Poder y sociedad en el Perú. Lima: IEP-IFEA.

BURGA, Manuel

1981 Apogeo y crisis de la República Aristocrática. Lima: Rikcjay.

CONTRERAS, Carlos

1999 Historia del Perú Contemporáneo. Lima: Red para el desarrollo de las Ciencias Sociales en el Perú.

CORNEJO, David

1953 Don Manuel Pardo y la Educación Nacional. Lima: PUCP.

COTLER, Julio

1978 Clases, Estado y nación en el Perú. Lima: IEP.

ENCINAS, José

1932 Un ensayo en la escuela nueva en el Perú. Lima: Imprenta Minerva.

GILBERT, Denis

1982 La oligarquía peruana: historia de tres familias. Lima: Horizonte.

GONZALES, Osmar

2005 El gobierno de Guillermo E. Billinghurst. Los orígenes del populismo en el Perú. 1912-1914. Lima: Mundo Nuevo.

MANRIQUE, Nelson

1995 Nuestra historia: Historia de la República. Lima: COFIDE.

MARTÍNEZ, Ricardo

1945 Apuntes para una interpretación marxista de historia social del Perú. Lima: Compañía impresora peruana S.A.

MARIATEGUI, José Carlos

1957 Siete ensayos de la interpretación de la Realidad Peruana. Lima: Minerva.

1980 Temas de educación. Lima: Minerva.

MC EVOY, Carmen

1997 La Utopía Republicana: Ideales y Realidades en la Formación de la Cultura Política. Lima: PCUP.

2004 La huella republicana liberal en el Perú. Manuel Pardo. Escritos Fundamentales. Lima: Fondo Editorial del Congreso del Perú.

PEZO, César

1981 El magisterio y sus luchas: 1885-1978. Lima: Ediciones DESCO. 
PORTOCARRERO, Felipe

1995 El imperio Prado: 1890-1970. Lima: CIUP.

QUIJANO, Aníbal

1978 Imperialismo, clases sociales y estado en el Perú 1890 - 1930. Lima: Mosca Azul.

ROEL, Virgilio

1986 El Perú en el siglo XIX. Lima: El Alba E.I.R.L.

THORP, Rosemary

1985 Perú 1890 - 1977 crecimiento y políticas en una economía abierta. Lima: Mosca azul.

VARCARCEL, Carlos

1975 Breve historia de la Educación Peruana. Colección Ciencias Sociales, Lima: Editorial Educación.

YEPES, Ernesto

1971 PERÚ: 1820-1920 ¿Un siglo de desarrollo capitalista? Lima: Signo Universitario. 